\title{
HÀM Ý HộI THOẠI TRONG PHIM KINH ĐIỂN "SPOTLIGHT"
}

\author{
Nguyễn Quang Ngoạn*, Cao Văn Hương \\ Khoa Ngoại ngũu, Trường Đại học Quy Nhơn, 170 An Dưong Vương, \\ Tp. Quy Nhơn, Bình Định, Việt Nam \\ Nhận bài ngày 08 tháng 08 năm 2017 \\ Chỉnh sửa ngày 31 tháng 08 năm 2017; Chấp nhận đăng ngày 29 tháng 09 năm 2017
}

Tóm tắt: Trên cơ sở lý thuyết về hàm ý hội thoại (conversational implicature) của Grice (1975), bài báo phân tích các cách thức biểu đạt hàm ý hội thoại dựa trên ngữ liệu từ tác phẩm điện ảnh kinh điển "Spotlight" (đoạt giải Oscar 2015). Ngữ liệu nghiên cứu được thu thập từ hội thoại của các nhân vật chính là thành viên của đội điều tra Spotlight. Tổng cộng 41 đoạn hội thoại trong phim cho thấy có sự "cố ý vi phạm" các phương châm hội thoại. Từ ngữ liệu được phân tích, các tác giả dùng thao tác suy ý (inference) để tìm ra hàm ý của tham thể giao tiếp. Kết quả nghiên cứu cho thấy sự vi phạm phương châm về "quan hệ" và "chất" chiếm đa số trong khi sự vi phạm phương châm về "cách thức" không đáng kể.

Tù khóa: hàm ý hội thoại, nguyên tắc cộng tác, phương châm hội thoại, sự vi phạm

\section{Dẫn nhập}

Trong giao tiếp để tránh tình trạng "ông nói gà, bà nói vịt”, "hỏi một đàng, đáp một néo”... giữa người nói và người nghe cần có sự cộng tác. Grice (1975) lý thuyết hóa sự cộng tác này thành "Nguyên tắc cộng tác" (Cooperative Principle). Nguyên tắc cộng tác cho rằng phải làm cho phần đóng góp của bạn (vào cuộc thoại) đúng như nó được đòi hỏi vào giai đoạn mà nó xuất hiện, phù hợp với mục đích hay phương hướng mà bạn đã chấp nhận tham gia vào. Nguyên tắc cộng tác được chi tiết hóa thành bốn phương châm hội thoại: "luợng" (quantity), "chất” (quality), "quan hệ" (relation) và "cách thức” (manner).

Tuy nhiên trong thực tế giao tiếp, không phải lúc nào người nói cũng tuân theo nguyên tắc cộng tác này mà thường "cố tình" vi phạm chúng. Trong trường hợp người nói hợp tác nhưng vẫn cố tình vi phạm các phương châm, thì ngoài ý nghĩa trực tiếp của phát ngôn nhờ các yếu tố ngôn ngữ như ngữ âm, từ vựng, cú

\footnotetext{
* Tác giả liên hệ. ĐT.: 84-911308279

Email: nguyenquangngoan@qnu.edu.vn
}

pháp ... còn có các ý nghĩa khác mà để hiểu phát ngôn, người nghe phải dùng đến các thao tác "suy ý" (inference) dựa vào ngữ cảnh, các quy tắc điều khiển hành vi ngôn ngữ, điều khiển lập luận v.v... mới nắm bắt được. Loại ý nghĩa này được gọi là hàm ý. Nói cách khác, hàm ý là ý ở ngoài lời.

Việc nghiên cứu hiện tượng hàm ý rất hữu ích và thú vị nếu nguồn ngữ liệu vừa phản ánh thực tế giao tiếp trong đời sống, vừa là sản phẩm các bậc thầy về ngôn ngữ sáng tạo ra (như thơ, truyện ngắn, tiểu thuyết...). Chính vì vậy, chúng tôi chọn ngữ liệu là các đoạn hội thoại có chứa hàm ý trong phim "Spotlight". Đây là bộ phim dựa trên một câu chuyện có thật xảy ra ở Mỹ vào cuối những năm 1990 liên quan đến tình trạng ấu dâm của các linh mục công giáo. Bộ phim được trao giải Oscar năm 2015 cho hạng mục phim xuất sắc nhất. Sở dĩ chúng tôi chọn phim này làm ngữ liệu nghiên cứu là vì hàm ý được sử dụng khá phổ biến trong phim. Thêm nữa, các yếu tố ngữ cảnh trong phim rất rõ ràng giúp cho việc xác định và kiến giải hàm ý thêm thuận lợi. 
Trong phạm vi bài báo này, chúng tôi nhắm đến việc xác định phương châm hội thoại nào là phương châm hay bị "vi phạm” và thử lý giải hàm ý được tạo ra do sự cố tình vi phạm (các) phương châm hội thoại đó. Để đạt được mục đích trên, chúng tôi sẽ phân loại các đoạn hội thoại dựa vào phương châm bị vi phạm: lượng, chất, quan hệ, và cách thức. Ngoài bốn phương châm riêng lẻ trên chúng tôi còn thêm vào một trường hợp khi có nhiều hơn một phương châm hội thoại bị vi phạm. Chúng tôi gọi đó là sự "vi phạm đa phuoong châm".

Trong giới hạn của bài viết, chúng tôi chỉ nghiên cứu "hàm ý hội thoại đặc thù" (particularized implicature). "Hàm ý thang độ" (scalar implicature) và "hàm ý hội thoại tổng quát” (generalized implicature) không phải là đối tượng nghiên cứu của công trình này. Các phân tích hàm ý hội thoại trong công trình được dựa trên lý thuyết về "hàm ý hộ thoại" (conversational implicature) đề xuất bởi Grice (1975). Các ví dụ minh họa được đưa ra mang tính chất đại diện trong khuôn khổ giới hạn của một bài báo.

\section{Co' sở lý thuyết}

Lý thuyết hàm ý hội thoại được Grice (1975) đề xuất đầu tiên vào những năm 1960 khi ông đăng những bài báo đầu tiên về lĩnh vực này. Ông phát triển lý thuyết mang tính nền móng này để tìm ra cơ chế và giải thích cách mà hàm ý được tạo ra và lĩnh hội như thế nào. Trong lý thuyết hàm ý hội thoại, "nguyên tắc cộng tác"(cooperative principle) và bốn phương châm hội thoại đã nêu đóng vai trò trung tâm. Theo ông nếu người nói cố tình vi phạm phương châm hội thoại nhưng vẫn có tinh thần cộng tác, anh ta đang tạo ra hàm ý.

Ví dụ sau là tham thoại của hai nhân vật là hai phụ nữ sống ở miền biển:

A: Dạo này công việc của $C$ nhu thế nào?

$B$ : Ổ, biển lặng và không phải mùa trăng.

Rõ ràng trong cuộc thoại này $B$ đã vi phạm phương châm về quan hệ. Câu trả lời của $\mathrm{B}$, nếu căn cứ vào hiển ngôn, không phải là câu trả lời thỏa đáng. Tuy vậy, không có lý do gì để $\mathrm{A}$ cho rằng $\mathrm{B}$ không cộng tác. Vì vậy để làm cho câu trả lời mang tính quan yếu, người nghe phải dùng đến thao tác suy ý. Đến đây, chúng ta xem xét khả năng A có thể rút ra được hàm ý gì. Theo logic thông thường, đối với người miền biển thì biển lặng và không có trăng là thời điểm thích hợp nhất để ra khơi đánh cá. Như vậy là công việc được tiến hành thuận lợi. Nếu công việc của ngư dân thuận lợi thì công việc của $C$ cũng tốt theo. Do vậy có thể $\mathrm{B}$ muốn hàm ý rằng công việc của $C$ là tốt và nghĩ rằng $\mathrm{A}$ hiểu được hàm ý này vì A chia sẻ kiến thức nền về văn hoá (shared cultural background) với $\mathrm{B}$.

Như vậy, A có nhiều điểm thuận lợi hơn trong việc hiểu phát ngôn và đưa "sai số" về giới hạn nhỏ và trong đa số trường hợp là bằng không. Trong khi đó, nếu là người phân tích hội thoại, không ở vị trí thuận lợi như các tham thể giao tiếp thì chúng ta chỉ có thể nghiên cứu ý định “có thể có" mà thôi. Tuy nhiên, giao tiếp luôn là một hoạt động đa dạng và phức tạp, vì vậy ngay cả đối với người nghe trực tiếp như là một tham thể giao tiếp, thì anh ta/cô ta cũng ở tình huống tương tự: không có cách nào để biết chính xác người nói đang nghĩ gì. Anh ta/ cô ta cũng chỉ có thể phán đoán ý định "có thể có” của người nói.

Bàn thêm về các phương châm hội thoại, Grice (1975) làm rõ các yêu cầu phải tuân thủ các phương châm về lượng, chất, quan hệ và cách thức như sau:

- Phương châm về chất: Hãy làm cho phần đóng góp của anh là đúng; đừng nói điều mà anh tin là sai hay điều mà anh tin là thiếu bằng chứng.

(Maxim of Quality: Try to make your contribution one that is true; do not say what you believe to be false or do not say that for which you lack adequate evidence.)

- Phương châm về lượng: Hãy làm cho phần đóng góp của anh có lượng thông tin đúng như đòi hỏi của mục đích cuộc thoại; 
đừng làm cho lượng thông tin của anh lớn hơn yêu cầu.

(Maxim of Quantity: Make your contribution as informative as is required for the current purposes of the exchange; do not make your contribution more informative than is required.)

- Phương châm về quan hệ: Hãy nói những điều có liên quan.

(Maxim of relation: Be relevant.)

"Relation" là thuật ngữ gốc mà Grice (1975) dùng. Sau này, có tác giả cũng gọi phương châm này là "relevance" (quan yếu), tức là thông tin mà người nói đưa ra phải có liên quan thiết yếu đến nội dung cuộc thoại đang diễn ra.

- Phương châm về cách thức: Phải rõ ràng. Cụ thể là phải tránh tối nghĩa; tránh mơ hồ; phải ngắn gọn; và phải theo thứ tự.

(Maxims of Manner: Be perspicuous. Avoid obscurity of expression; Avoid ambiguity; Be brief (Avoid unnecessary prolixity); Be orderly.)

Trong tiếng Việt, thuật ngũ̃ "implicature" được gọi là "hàm ngôon" (Đỗ Hữu Châu, Bùi Minh Toán, 1996; Đỗ Thị Kim Liên, 1999) hay "hàm ý" (Nguyễn Đức Dân, 1996; Nguyễn Thiện Giáp, 2003). Các nhà ngôn ngữ học này cũng giới thiệu và đi sâu bàn luận về nội hàm cũng như tính chất của khái niệm này trong tiếng Việt. Ở đây, "hàm ý mà chúng tôi muốn nói đến là "hàm ý hội thoại", tức là ý nghĩa cuối cùng mà người nói muốn người nghe hiểu được thông qua một cách nói nào đó, không tuân theo các phương châm hội thoại và dựa trên ngữ cảnh giao tiếp và kiến thức, thông tin chung chia sẻ giữa người nói và người nghe. Xung quanh vấn đề này, mới đây ở Việt Nam có những nghiên cứu thú vị theo quy mô đề tài luận văn thạc sĩ. Chẳng hạn, Võ Thị Thanh Thảo (2012) nghiên cứu về hàm ý hội thoại trong phim "Titanic". Nghiên cứu này nhằm tìm ra các loại hàm ý được sử dụng trong phim và giải thích nguyên nhân cũng như hiệu quả của việc sử dụng hàm ý. Tuy nhiên, việc cung cấp thiếu đầy đủ các yếu tố ngữ cảnh đã làm cho việc diễn giải hàm ý của tác giả còn nhiều chỗ ít nhiều mang tính chủ quan và chưa thực sự thuyết phục. Nguyễn Thị Tú Anh (2012) nghiên cứu hàm ngôn trong truyện ngắn của Nguyễn Huy Thiệp bằng cách đi sâu phân tích hàm ngôn được sử dụng trong các truyện ngắn được khảo cứu và các giá trị biểu đạt của chúng. Ngoài ra, tác giả cũng mô tả và phân loại cơ chế kiến tạo hàm ngôn cùng các chức năng giao tiếp của nó. Đoàn Thị Tâm (2006) cũng nghiên cứu về phương thức tạo hàm ngôn trong truyện cười tiếng Việt và tác giả đã thành công trong việc giới thiệu 33 phương thức tạo hàm ngôn trong tiếng Việt. Các nghiên cứu ngày đã giúp cho chúng tôi rất nhiều trong việc xác định hàm ý hội thoại trong phim "Spotlight", góp phần tăng tính thuyết phục cho việc kiến giải hàm ý dựa trên các yếu tố ngữ cảnh và kiến thức chung của các tham thể giao tiếp trong nguồn hội thoại được phân tích.

\section{Phương pháp nghiên cứu}

Để tìm hiểu phương thức biểu đạt hàm ý dựa trên sự cố tình vi phạm các phương châm hội thoại, chúng tôi sử dụng chủ yếu là phương pháp diễn dịch. Những tính toán có tính chất "định luợng” (như thống kê) chỉ nhằm hỗ trợ cho sự bao quát chung về tần suất sử dụng của mỗi loại hàm ý. Tất cả các phát ngôn đều được chúng tôi đặt trong ngữ cảnh đủ rộng để tìm ra ý nghĩa đích thực mà chủ thể phát ngôn muốn thông báo.

\section{Kết quả}

Dựa trên các cơ sở trên, khi khảo sát tác phẩm điện ảnh "Spotlight" chúng tôi thống kê được có hơn 170 đoạn hội thoại có sự vi phạm về phương châm hội thoại để tạo ra hàm ý. Tuy nhiên do giới hạn của bài báo, chúng tôi chỉ nghiên cứu 41 đoạn hội thoại có các phát ngôn của các thành viên đội phóng viên điều tra Spotlight. Kết quả cụ thể về sự vi phạm các phương châm được thể hiện trong Bảng 1 . 
Bảng 1. Tần suất vi phạm phương châm hội thoại của Grice

\begin{tabular}{|c|c|c|c|}
\hline $\begin{array}{c}\text { Thứ } \\
\text { tự }\end{array}$ & $\begin{array}{c}\text { Phương châm } \\
\text { bị vi phạm }\end{array}$ & $\begin{array}{c}\text { Số } \\
\text { lượng }\end{array}$ & Tỷ lệ (\%) \\
\hline 1 & Lượng & 8 & $\mathbf{1 9 . 5 1}$ \\
\hline 2 & Chất & 10 & $\mathbf{2 4 . 3 9}$ \\
\hline 3 & Quan hệ & 13 & $\mathbf{3 1 . 7 0}$ \\
\hline 4 & Cách thức & 3 & $\mathbf{7 . 3 2}$ \\
\hline 5 & $\begin{array}{c}\text { Đa phương } \\
\text { châm }\end{array}$ & 7 & $\mathbf{1 7 . 0 8}$ \\
\hline Tổng & & $\mathbf{4 1}$ & $\mathbf{1 0 0}$ \\
\hline
\end{tabular}

Kết quả cho thấy sự vi phạm phương châm về quan hệ để tạo ra hàm ý chiếm tỷ lệ cao nhất với 13 lần xuất hiện. Xin xét một số ví dụ điển hình sau đây:

a. Trường hợp vi phạm phương châm về chất.

Ở đây, chúng tôi xin nêu ra hai ví dụ điển hình cho hàm ý hội thoại được tạo ra từ sự vi phạm phương châm về chất có chủ đích: Ví dụ (1) và (2).

(1)

- Mike: Anh ta nói các linh mục đều nhắm vào cùng kiểu nạn nhân: con nhà thu nhập thấp, không cha, gia đình tan vỡ...Vậy là những gã như Geoghan tìm đến trẻ em nam không phải vì hắn thích chúng hơn mà vì bọn trẻ đó dễ xấu hổ, ít khả năng kể cho người khác. Nhũng $\boldsymbol{g} \tilde{\boldsymbol{a}}$ này là kẻ săn mồi, Robby à. Sipe nói anh ta gặp hàng tá những kẻ như vậy từ những năm 60 ở Seton. Anh ta gọi đó là "một hiện tương".

(He said they all target the same kinda kid. Low income family, absentee father, broken home...And guys like Geoghan go after boys not cause they prefer them, but cause they're more ashamed, less likely to talk. These guys are predators, Robby. Sipe says he saw dozens of them at Seton in the 60's. He called it "a phenomenon").

- Robby: Vậy sao anh ta không công khai?

(Why didn't he go public?)

Mike và Robby đang nói chuyện về các linh mục lạm dụng trẻ em nam. Theo như bác sỹ tâm thần Sipe, người bỏ hơn 30 năm nghiên cứu về hiện tượng các linh mục có lệch lạc về tình dục, đây là một dạng bệnh tâm thần. Mike đã vi phạm phương châm về chất khi gọi các linh mục đó là "kẻ săn mồ $i$ ". Để lý giải được được câu nói mang tính ẩn dụ này, Robby phải đi từ các tập tính của kẻ săn mồi. Chúng hay lựa chọn con mồi là các đối tượng yếu đuối nhất, chậm chạp nhất, ít có khả năng tự vệ nhất...Và khi chúng đã chọn được con mồi nào, chúng sẽ không dễ dàng từ bỏ mục tiêu đó. Vì vậy, trong trường hợp này Mike hàm ý các linh mục này sẽ không bao giờ từ bỏ việc săn lùng các cậu bé, đặc biệt là các cậu bé xuất thân từ các gia đình dễ bị tổn thương nhất.

(2)

- Robby: Trời, anh ta có bao giờ về nhà không vậy?

(Does he ever go home?)

- Ben: Hầu như không. Tôi có những nhân viên không dám về trước anh ta; $\boldsymbol{a n h}$ ta ngồi mòn hết cả cái tòa soạn chết tiệt này rồi.

(Apparently not. I got guys who won't leave til he does, he's wearing out the goddam newsroom.)

Đoạn hội thoại xảy ra khi Ben và Robby rời nơi làm việc khi đêm đã rất muộn. Thế nhưng trong văn phòng của tổng biên tập Marty đèn vẫn còn sáng và ông ta vẫn làm việc ở đó. Bằng câu trả lời có phần cường điệu, Ben đã cố ý vi phạm phương châm về chất. Trong trường hợp này không khó để Robby có thể hiểu được Ben đã hàm ý điều gì. Tuy vậy chúng ta hãy thử đánh giá hiệu quả của việc Ben lựa chọn phương thức tạo hàm ý bằng cách vi phạm phương châm về chất so với việc anh ta sử dụng nghĩa tường minh để trả lời câu hỏi của Robby. Hãy tưởng tượng cuộc sống của con người sẽ trở nên nhàm chán như thế nào nếu quá trình giao tiếp chỉ đơn thuần là sự gửi và nhận loại thông tin lõi thuần túy, kiểu như ngôn ngữ máy tính. Thực tế, sự thành công của quá trình giao tiếp còn được đánh giá dựa trên nghệ thuật sử dụng ngôn từ. Ngôn từ còn dùng để biểu đạt được thái độ của người nói đối với một đối tượng cụ thể. Để 
ngồi mòn một nơi, người ta cần có nhiều thời gian, công sức kể cả với sự trợ giúp của nhiều loại phương tiện khác nhau. Nói một người ngồi mòn cả tòa báo là nói hơi quá điều người nói tin là đúng và ngoài việc chuyển tải được hàm ý rằng người đó làm việc rất chăm chỉ, nó còn thể hiện được sự thán phục và ngưỡng mộ của Ben đối với vị tổng biên tập của mình.

b. Trường hợp vi phạm phương châm về lượng.

Chúng ta hãy xem xét các trường hợp ví dụ (3) và (4) như các trường hợp vi phạm phương châm về lượng điển hình trong tác phẩm được nghiên cứu.

(3)

Mike: Hey, không phải anh đang golf với bạn à?

(Hey. Shouldn't you be golfing?)

Robby: Golf không phải là một động tù: Và hôm nay tôi không có thời gian để chơi.

(Golfing's not a verb. And I couldn't get a tee time today.)

Mike: Người ta gọi nó thế à? Thời gian để chơi?

(Is that what they call it? A tee time?)

Robby: Họ cũng gọi nó là thời gian thư giãn nữa. Anh nên thử.

(They also call it a leisure activity. You should try it, Mike.)

Câu trả lời của Robby "Golf không phải là một động tù" "không cung cấp đủ thông tin cho câu hỏi của Mike. Rõ ràng chẳng có thông tin gì mới trong phát ngôn của Robby, golf không phải là động từ là một điều hiển nhiên mà ai cũng biết. Để tìm được ý nghĩa thực sự của phát ngôn này, các kiến thức về môn golf là rất cần thiết. Để chơi golf người ta phải mất nhiều thời gian, và người ta không chơi golf khi bận bịu với công việc. Vì vậy, Robby hàm ý rằng anh không thể chơi golf vì việc đó chiếm mất nhiều thời gian.

Saviano: Cô đang bỏ rơi chúng tôi! Có lẽ tôi nên đưa câu chuyện sang cho tờ Herald.

(You're dropping us! Maybe I should tell the Herald that story!)
Sacha: Được rồi, Phill. Thích thì anh cứ làm vậy. Nó sẽ đổ sông đổ bể mọi công sức của chúng tôi. Tôi không cản được. Anh nghe này. Tôi ngồi đây vì tôi quan tâm. Chúng tôi không đi đâu cả. Không đi đâu cả. Chúng tôi sễ viểt câu chuyện này. Chúng tồi sẽ viết nó một cách chính xác. Chúng tôi chỉ cần thêm thò̀ gian. Chỉ cần thế thôi.)

(Okay, Phil. You can do that if you like, it'll undo all the work we've done. But I can't stop you. Listen to me. I am here because I care. We are not going away. We are not going away. We are going to tell this story and we're going to tell it right. We just need more time, that's all we're asking for.)

Saviano: Vậy cô cần hỏi làm gì? Đằng nào các cô chả làm thế. Các người luôn như thế.

(Why bother asking? You're gonna do what you want anyway. You always do.)

Để hiểu được hàm ý trong phát ngôn của Sacha là gì chúng ta cần đặt chúng vào hoàn cảnh mà cuộc thoại này diễn ra. Saviano là nạn nhân của việc bị các linh mục xâm hại tình dục khi ông vừa mới hơn mười tuổi. Và cũng như nhiều nạn nhân khác, ký ức khủng khiếp và cảm giác mặc cảm tội lỗi đã luôn đeo bám ông đến suốt cả cuộc đời. Dù vậy, người cha của ba đứa con này vẫn còn may mắn hơn nhiều nạn nhân khác: một số tự tử, số khác nghiện ngập hoặc sống cuộc đời còn lại trong bệnh viện tâm thần... Mặc dù không thể quên được ký ức đó, ông vẫn cố chôn vùi và giấu kín ngay cả với người vợ của mình. Vậy mà, Sacha, phóng viên báo Global Boston, đến và thuyết phục ông kể lại câu chuyện của mình. Cô đã làm ông tin tưởng rằng bằng cách công khai các thông tin, ông có thể giải phóng cho chính mình và cứu được nhiều nạn nhân khác. Niềm tin mà ông dành cho Sacha càng lớn thì sự giận dữ của ông càng cao nếu Sacha không đi đến cùng sự việc. Vụ khủng bố ngày 11 tháng 9 đột ngột xảy ra đã thu hút sự chú ý của toàn bộ báo giới và các vụ khác phải tạm thời không được ưu tiên tập trung, kể cả vụ các 
linh mục lạm dụng tình dục trẻ em. Sacha hiểu được sự thất vọng và giận dữ đó của Saviano, nên cô cố thuyết phục Saviano tin rằng họ sẽ không từ bỏ vụ này. Cô đã vi phạm phương châm về lượng khi cung cấp nhiều thông tin hơn cần thiết vào thời điểm cuộc thoại diễn ra. Càng nhiều thông tin chứng minh họ không từ bỏ các nạn nhân như Saviano thì độ khả tín của phát ngôn càng tăng. Đó là lý do vì sao phương châm về lượng bị cố ý vi phạm trong trường hợp này. Hàm ý mà phát ngôn này chuyển tải là đề nghị Saviano đừng mất niềm tin vào báo Global Boston vì rằng các phóng viên sẽ đưa tin chính xác, đến cùng.

c. Trường hợp vi phạm phương châm về quan hệ.

Các ví dụ điển hình (5) và (6) sau đây phần nào giúp người đọc hiểu rõ hơn sự vi phạm phương châm về quan hệ trong tác phẩm điện ảnh "Spotlight".

(5)

Ben: Anh đi đâu thế?

(Where are you going?)

Robby: Tới buổi họp 10:30.

(To the 10:30.)

Ben: Anh hả? Từ bao giờ thế?

(You? Since when?)

Robby: Này trên lý thuyết tôi là biên tập viên đấy nhé.

(Technically, I am an editor.)

Ben: Trên lý thuyết. Cuộc gặp của anh với Baron tốt đến thế sao

(Technically. Your sit-down with Baron go that well?)

Câu trả lời của Robby, thoạt đầu có vẻ chẳng có gì liên quan đến câu hỏi của Ben. Robby đã vi phạm phương châm về quan hệ: phải quan yếu. Để làm cho câu trả lời quan yếu Ben phải giữ vững tiền ước là Robby hợp tác. Quá trình suy ý phải dựa trên nền kiến thức sau đây. Tòa soạn của báo Global Boston có những cuộc họp lúc 10:30 chỉ dành các nhân vật chủ chốt từ biên tập viên trở lên. Thế nhưng sao cuộc gặp giữa Robby và vị tổng biên tập mới (Baron), Robby lần đầu tiên được tham dự cuộc họp này. Như vậy Robby hàm ý rằng việc anh được tham dự cuộc họp quan trọng trên được quyết định từ lúc anh gặp Baron và trở thành một biên tập viên.

(6)

Matt: Tôi mới ở phòng tin tức, thẩm phán Sweeney đã lên lịch cho phiên tòa rồi.

(I was just in the newsroom, Judge Sweeney set a date for the hearing.)

Robby: Khi nào?

(When?)

Matt: Hai tuần. Canellos đã cá cược. 10 đô để được vào.

(Two weeks. Canellos started a pool. Ten bucks to get in.)

Robby: Có ai chọn Globe không?

(Anyone picking the Globe?)

Matt: Anh ta chỉ cuọc bà Sweeney sẽ xủ chúng ta thua trong bao lâu thôi.

(He's only taking bets on how fast Sweeney rules against us.)

Khi Global Boston yêu cầu tòa án cho họ tiếp cận với các tài liệu liên quan đến linh mục ấu dâm, không có nhiều người tin rằng họ sẽ được tòa án cho phép. Canellos đã cá cược liên quan đến vụ này. Trả lời cho câu hỏi của Robby, Matt đã vi phạm phương châm về quan hệ khi không trả lời có hay không có người chọn Global. Khi nói "Anh ta chỉ cuợc bà Sweeney sẽ xủ chúng ta thua trong bao lâu thôi”, Matt muốn chuyển tải hàm ý rằng chẳng có ai chọn Globe cả.

$\mathrm{d}$. Trường hợp vi phạm phương châm về cách thức.

Chúng tôi xin được giới thiệu hai ví dụ (7) và (8) sau đây cho phần phân tích hàm ý được tạo ra từ sự cố ý vi phạm phương châm về cách thức trong tác phẩm điện ảnh "Spotlight".

(7)

Jim: Tôi mới gặp tổng mới của anh, có vẻ là một gã chơi được.

(I just met your new editor, seem like a decent fella.)

Robby: Tôi cũng nghĩ thế. Này, tôi có một cuộc nói chuyện rất hay ho với Eric MacLeish hôm rồi. Hóa ra anh ta từng hòa giải mấy vụ lạm dụng với Tổng giám mục nhiều năm liền. 
(I think he is. I had an interesting conversation with Eric MacLeish yesterday. Turns out to be he's been settling abuse cases with the archdiocese for years.)

Jim: Anh thực sự muốn nói chuyện đó ở đây sao?

(You really want to talk about this here?)

Robby: Jim, anh nói anh từng giúp cha Barrett, và chỉ một lần rồi thôi sao? Anh tham gia bao nhiêu vụ trong số đó rồi?

(You said you helped out on Father Barrett as a favor, that was a one-off? How many of these cases have you been involved with, Jim?)

Jim: Anh biết tôi không thể trả lời mà. Thế là phi đạo đức nghề nghiệp.

(You know I can't answer that, Robby. It's unethical.)

\section{Robby: Chỉ có thế thôi sao?}

(Is that all it is?)

Cuộc thoại này diễn ra giữa Robby, biên tập báo Global Boston, và luật sư Jim, một trong số các luật sư đã giúp tòa Tổng giám mục Boston hòa giải các vụ linh mục lạm dụng trẻ em và các nạn nhân một cách riêng tư (không công khai). Câu hỏi cuối cùng của Robby thực ra không phải là câu hỏi để biết thêm thông tin, vì cả Jim lẫn Robby đều biết câu trả lời. Robby đã vi phạm phương châm về cách thức khi chọn cách diễn đạt một cách mập mờ. Thế nhưng để hiểu rõ được tính mập mờ trong phát ngôn của Robby chúng ta cần biết kiến thức nền dẫn đến cuộc thoại này. Ở giáo phận Boston có gần một trăm linh mục ấu dâm ( $6 \%$ trong tổng số linh mục), nhưng khi có báo cáo lên tòa Giám mục, thay vì xử lý các linh mục này, Hồng y Law lại giấu nhẹm. Ông chọn cách luân chuyển các linh mục này sang các khu vực khác và dùng các luật sư riêng để “hòa giải' với các nạn nhân. Các nạn nhân được nhận một số tiền "đền bù” (không quá hai chục ngàn đô la), nhưng bù lại họ phải cam kết không được đưa các vụ việc ra tòa án. Các nạn nhân, phần vì xuất thân trong các gia đình ít học, phần vì bị sức ép của giáo hội... đã chấp nhận. Các luật sư tham gia hòa giải cũng phải cam kết không công khai các tin tức về các vụ hòa giải này và được hưởng $1 / 3$ tổng số tiền cho mỗi vụ hòa giải. Có tổng số 90 linh mục mục ấu dâm và mỗi linh mục có nhiều nạn nhân khác nhau nên tổng số tiền "hòa giải " mà các luật sư kiếm được nhờ vào hành vi vô đạo đức của mình là rất đáng kể. Đó là lý do tại sao khi Jim nói rằng không thể tiết lộ về số vụ "hòa giải" vì như vậy là phi đạo đức nghề nghiệp, Robby lựa chọn cách diễn đạt mập mờ "Chỉ có thể thôi sao?". Chúng ta có thể rút ra rằng Robby muốn hàm ý rằng thực ra tôi biết tỏng lý do vì sao anh ngậm miệng ăn tiền rồi, rằng anh đừng đem cái lý do đạo đức nghề nghiệp ra để lòe tôi, rằng anh là một loại kền kền mà thôi...

(8)

Mike: Thế thì đến tết Công gô mới xong. (That's gonna take a load of time.)

Robby: Sẽ không lâu nếu tất cả chúng ta cùng xắn tay vào.

(Not if we're all on it.)

Mike: Cả anh luôn à?

(You too?)

Robby: Co'bản thì tì̀ "tất câ" có nghĩa đó. (Generally, that's what all means.)

Mike: Đúng vậy, về cơ bản.

(Yeah, generally.)

Khi các phóng viên phát hiện số lượng linh mục ấu dâm ngày càng nhiều, họ nghi ngờ rằng Tòa tổng giám mục có biết các vụ việc đó nhưng họ thông đồng để giấu nhẹm. Tuy nhiên việc tìm ra tất cả các linh mục ấu dâm này không dễ vì các nạn nhân và kể cả chính quyền đều ngại Tòa tổng giám mục. Các phóng viên phát hiện rằng bằng cách theo dấu ngược các cuốn danh bạ trong đó các linh mục nào được mô tả là "nghi bệnh" hoặc "chura bổ nhiệm” đều có thể liên quan đến việc lạm dụng tình dục trẻ em và bị Tòa tổng giám mục cho tạm nghỉ hoặc luân chuyển sang giáo phận khác. Việc này rất mất thời gian và cần nhiều người. Khi Mike hỏi Robby "Cả anh luôn à? ” Robby đã cố ý vi phạm phương châm về 
cách thức khi ông diễn đạt một cách mơ hồ "Co bản thì tù 'tất cả' có nghĩa đó". Phương châm về cách thức quy định người nói phải tránh diễn đạt phức tạp, mơ hồ mà phải một cách rõ ràng. Với cách diễn đạt này, Robby muốn chuyển tải hàm hàm ý rằng kể cả mình cũng sẽ tham gia vào việc dò các cuốn danh bạ để xác định các linh mục ấu dâm.

e. Trường hợp vi phạm đa phương châm hội thoại.

Trong nhiều trường hợp mẫu ngữ liệu mà chúng tôi chọn khảo cứu trong phim "Spotlight", có hiện tượng nhiều hơn một phương châm của Grice bi cố ý vi phạm để tạo ra hàm ý. Sau đây là hai ví dụ điển hình từ ngữ liệu thu được, ví dụ (9) và (10).

(9)

Robby: Vâng. Cảm ơn Ben. Chắc thế. Mặc dù tôi để bụng chuyện anh lôi tuổi tác của tôi ra, tôi phải nói việc Stewart rời đi đặc biệt đau đớn với tôi. Bởi vì.... bao lâu nhỉ, Stewart? 20 năm nay Stewart luôn sẵn lòng chi tiền trên bàn poker. Và tôi có con đi học đại học.

(Thanks, Ben. I think. And although I take issue with the reference to my seniority, I will say Stewart's departure is especially painful for me. You see, for... what? 20 years now, Stewart's been more than willing to part with his money at the poker table... And I got a kid in college.)

Stewart: Ồ, nhưng tôi vẫn chơi mà. (Yeah, but I'm gonna keep playing.)

Robby: Vậy thì vấn đề đã được giải quyết. Thượng lộ bình an nhé.

(Problem solved. Godspeed, buddy.)

Sau hơn 20 năm làm việc cùng nhau, cuối cùng Stewart đã rời báo Global Boston. Khi được Ben mời lên phát biểu vì là người có thâm niên làm việc lâu nhất tại Global Boston, Robby đã vi phạm đến 3 phương châm hội thoại. Đầu tiên đó là phương châm về cách thức: hãy ngắn gọn. Robby đã diễn đạt một cách dài dòng. Thứ hai, anh ta đã vi phạm phương châm về chất: đừng nói điều anh tin là sai. Bởi vì không có chuyện Stewart sẵn lòng chi tiền trên bàn poker. Stewart phải chi tiền bởi vì anh ta thua bài, không phải vì sẵn lòng. Cuối cùng Robby đã vi phạm phương châm về quan hệ: hãy quan yếu. Việc anh ta thông báo mình có con học đại học chẳng liên quan gì đến chủ đề của cuộc gặp mặt vào thời điểm đó. Điều rõ ràng là việc anh ta đồng thời vi phạm nhiều phương châm hội thoại phải hàm ý một điều gì đó bên ngoài các ý nghĩa tường minh trong phát ngôn của mình. Việc diễn giải dài dòng thực ra chỉ làm tăng thêm hiệu quả của việc anh ta muốn chế nhạo Stewart luôn luôn thua bài. Vậy có mối liên hệ gì giữa việc Robby đau khổ vì sự ra đi của Stewart và việc anh ta có con học đại học? Quá trình suy ý phải dựa vào thực tế là việc đại học cần rất nhiều chi phí còn việc Stewart ra đi có nghĩa là Robby mất đi nguồn tài chính phục vụ cho chi phí học tập của con mình. Vì vậy, có thể nói Robby muốn hàm ý mỉa mai rằng việc Stewart không còn chơi bài nữa làm anh lo lắng cho chi phí học đại học của con trai.

(10)

Robby: Eric, anh hòa giải với bao nhiêu linh mục? settle?)

(Eric, how many priests did you

Eric Macleish: Robby, anh biết mà. Tôi không thể nói được.

(You know I can't tell you, Robby.)

Robby: Anh sẽ phải cho tôi tên của chúng và tên của các nạn nhân.

(You're gonna give me their names. And the names of their victims.)

Eric Macleish: Anh đe dọa tôi à?

(Are you threatening me?)

Robby: Chúng tôi có hai câu chuyện ở đây. Một là về bọn tu sĩ suy đồi. Và một là câu chuyện về đám luật su biến các vụ lạm dụng trẻ em thành nghề riêng kiếm lợi. Giò anh muốn tôi viết câu chuyện nào đây? Vi chúng tôi sẽ chọn một trong hai...

(We've got two stories here. We've got a story about degenerate clergy and we've got a story about a bunch of lawyers turning child abuse into a cottage industry. Now, which story 
do you want us to write? Cause we're writing one of them ...)

MacLeish là một trong số các luật sư giúp Tòa tổng giám mục "hòa giải” với các nạn nhân, vì vậy anh ta không muốn cung cấp thông tin về nhân thân các linh mục và cả các nạn nhân cho các phóng viên. Phát ngôn của Robby khi trả lời câu hỏi của MacLeish đã vi phạm hai phương châm. Đầu tiên, rõ ràng anh ta đã vi phạm phương châm về lượng khi cung nhiều thông tin hơn cần thiết. Theo logic thông thường việc anh ta có ý định viết mấy câu chuyện không phải là thông tin mà MacLeish cần phải biết. Cũng như vậy nếu anh ta có định viết về các linh mục suy đồi hay không. Sau đó, khi đề cập đến "đám luật su biến các vu lạm dụng trẻ em thành nghề riêng kiếm lợ", anh ta đã vi phạm phương châm về cách thức khi dùng cách diễn đạt mập mờ. Mặc dù vậy, MacLeish vẫn nhận ra mối liên hệ giữa "đám luật su" và bản thân mình. MacLeish không thể cho rằng Robby cung cấp thừa thông tin và sự liên hệ mập mờ giữa các luật sư vô đạo đức và mình là do vô tình hay sự ngẫu nhiên, trái lại anh ta phải lý giải chúng trên cơ sở nguyên tắc cộng tác. Sự suy ý của MacLeish có thể diễn ra như sau: mình biết Robby muốn viết về các linh mục suy đồi chứ không phải các luật sư vô đạo đức, nhưng anh ta không thể viết nếu không có tên các linh mục và nạn nhân. Mình có thông tin về họ. Vậy mình phải cung cấp cho anh ta, nếu không anh ta sẽ viết về các luật sư (tức là viết về mình).

\section{Kết luận}

Trên đây là kết quả phân tích một số hàm ý hội thoại điển hình của các nhân vật chính trong phim "Spotlight" thông qua việc vận dụng lý thuyết về hàm ý hội thoại của Grice. Nghiên cứu cho thấy quá trình tạo hàm ý của người nói và lĩnh hội được hàm ý của người nghe là một quá trình rất phức tạp mà trong đó sự chia sẻ về ngữ cảnh giao tiếp bao gồm cả cảnh huống giao tiếp (situational context) và văn cảnh (linguistic context) cùng kiến thức, thông tin chung về văn hóa-xã hội (shared socio-cultural background) đóng vai trò cực kỳ quan trọng. Vì vậy, nói là "vi pham các phương châm hội thoại" nhưng thực ra đây là những vi phạm có chủ đích để người nói chuyển tải những hàm ý của mình mà thông qua ngữ cảnh và những hiểu biết chung, người nghe có thể dùng thao tác suy ý để hiểu được hàm ý của người nói là gì. Thiếu những yếu tố ngữ cảnh và hiểu biết chung, việc xác định hàm ý chắc chắn không thể tránh khỏi sự suy diễn sai lầm và dẫn đến sự thất bại của quá trình giao tiếp (mà trong thực tế giao tiếp vẫn thường xuyên xảy ra). Kết quả nghiên cứu cũng góp phần chỉ ra rằng hàm ý có thể được tạo ra do sự "cố tình vi phạm" nhiều hơn một phương châm cùng lúc. Việc phân tích hội thoại trong phim có giá trị cao trong việc áp dụng vào thực tế giao tiếp và dịch thuật, bởi lẽ hàm ý hội thoại trong phim thường phản ánh một cách chân thực quá trình giao tiếp trong thực tế hàng ngày.

\section{Tài liệu tham khảo}

\section{Tiếng Việt}

Nguyễn Thị Tú Anh (2012). Hàm ngôn trong truyện ngắn Nguyễn Huy Thiệp. Luận văn thạc sỹ, Đại học Sư phạm TP. Hồ Chí Minh.

Đỗ Hữu Châu, Bùi Minh Toán (1996). Đại cuoong ngôn ngũ học, Tập II. Hà Nội: Nxb Giáo dục.

Nguyễn Đức Dân (1996). Lô gic và Tiếng Việt. Hà Nội: Nxb Giáo dục.

Đỗ Thị Kim Liên (1999). Nhũng phưong thức cấu tạo hàm ngôn trong hội thoại. Hà Nội: Hội Ngôn ngũ học Việt Nam.

Đoàn Thị Tâm (2006). Một số phương thức tạo hàm ngôn trong truyện cuời tiếng Việt. Luận văn thạc sỹ, Đại học Sư phạm TP. Hồ Chí Minh.

Nguyễn Huy Thiệp (2005). Tuyển tập truyện ngắn. (Đỗ Hồng Hạnh tuyển chọn và hiệu đính). Nxb Văn hóa Sài Gòn.

\section{Tiếng Anh}

Bach, K. (1994). Conversational implicature. Mind and language, 9 (2), 124-162.

Grice, H. P. (1975). Logic and conversation. Cambridge: Cambridge University Press.

Võ Thị Thanh Thảo. (2012). A study of conversational implicatures in Titanic film. M.A. Thesis, Da Nang University. 


\title{
CONVERSATIONAL IMPLICATURES IN THE MOVIE "SPOTLIGHT"
}

\author{
Nguyen Quang Ngoan, Cao Van Huong \\ Department of Foreign Languages, Quy Nhon University, \\ 170 An Duong Vuong, Quy Nhon, Binh Dinh, Vietnam
}

\begin{abstract}
Based on the theory of conversational implicature by Grice (1975), the article discusses the ways to express implicature, with the data being the conversations in the famous movie, Spotlights, which was awarded an Oscar in 2015. The samples for analysis are the conversations in which the main characters who are members of the Sprotlight investigators participate. The total of 41 analyzed conversations show the "intended violation" of conversational maxims. By means of reference, the authors infer the conversational implicature of the characters. According to the result, most of the examples of implicature are created by violating the "relation" and "quality" maxim, while the "manner" maxim is the least violated.
\end{abstract}

Keywords: conversational implicature, cooperative principle, conversational maxim, violation 